\title{
Predicting Rooting Stages in Poinsettia Cuttings Using Root Zone Temperature-based Models
}

\author{
Erin G. Wilkerson and Richard S. Gates \\ Department of Biosystems and Agricultural Engineering, University of Kentucky, Lexington, KY 40546 \\ Sérgio Zolnier \\ Agricultural Engineering Department, Federal University of Viçosa, Brazil
}

Sharon T. Kester and Robert L. Geneve

Department of Horticulture, University of Kentucky, Lexington, KY 40546

\begin{abstract}
ADDiTIONAL INDEX wORDs. Euphorbia pulcherrima, thermal time, adventitious rooting, mist
Abstract. Root zone temperature optima for root initiation and root elongation stages for rooting in poinsettia (Euphorbia pulcherrima Willd. ex Klotzsch 'Freedom Dark Red') cuttings was determined to be 28 and $26^{\circ} \mathrm{C}$, respectively. Threshold temperatures where rooting development was slow ( $>24$ days) or did not occur were $\leq 20$ and $\geq 32{ }^{\circ} \mathrm{C}$. Time to visible rooting and postemergent root elongation was modeled based on cumulative daily mean root zone temperatures in growth chamber studies using a thermogradient table to provide simultaneous temperatures between 19 to $34{ }^{\circ} \mathrm{C}$. Time to root emergence at different root zone temperatures was best described using a nonlinear growth rate derived mathematical model, while postemergent root elongation up to $100 \mathrm{~cm}$ could be described using either a linear thermal time model or a nonlinear equation based on elongation rate. These temperature-based mathematical models were used to predict rooting in six greenhouse experiments. Using a root zone base temperature of $21^{\circ} \mathrm{C}$, observed vs. predicted time to visible root emergence was highly correlated $\left(r^{2}=0.98\right)$ with a mean prediction error (MPE) of $1.6 \mathrm{~d}$. Observed vs. predicted root length using the linear thermal time model had a $r^{2}=0.69$ and an MPE of $14.6 \mathrm{~cm}$, which was comparable to the nonlinear model with an $r^{2}=0.82$ and an MPE of $14.8 \mathrm{~cm}$.
\end{abstract}

Vegetatively propagated greenhouse crops are most commonly rooted from cuttings using intermittent mist to control water status of the cuttings prior to rooting. Mist control systems can be static or dynamic depending on the sophistication of the propagation facility (Hartmann et al., 2002). Static control is provided by dual system time clocks that separately set the mist duration and time interval between misting events. Changes in mist duration or interval must be changed manually at the propagator's discretion. Dynamic control relies on physical sensors or computational models to trigger mist events. Physical sensors include electronic leaves or leaf balances that are sensitive to evaporation of applied mist to a simulated leaf. Computational models use environmental data (solar radiation, temperature, and humidity) to estimate cutting evapotranspiration. Two common systems use accumulated light or calculated air vapor pressure deficit (VPDair) to trigger a mist event when the model predicts cutting evapotranspiration at a previously determined threshold (Zolnier et al., 2002, 2003).

Using an evapotranspiration-based misting model developed for poinsettia propagation (Zolnier et al., 2003), it was shown that dynamically controlled misting reduced water usage by up to $55 \%$ compared to statically controlled systems with no reduction in rooting quality under greenhouse conditions (Wilkerson et al., 2005). The evapotranspiration-based misting model incorporates a cutting coefficient that reflects the increased ability for cuttings to take up water from the medium as roots form on the cutting. The cutting coefficient effectively increases the set point used to trigger a misting event leading to less frequent misting as the cutting progresses to being fully rooted. Unlike other parameters in the evapotranspiration-based misting model, the cutting coef-

Received for publication 19 Aug. 2004. Accepted for publication 7 Nov. 2004. University of Kentucky Experiment Station publication \#04-11-122. This work was partially funded through a grant from the Gloeckner Foundation. ficient is based on time after sticking rather than being responsive to environmental conditions. It would benefit both dynamic and static mist propagation systems if the ability to predict the rooting stage in cuttings could be based on environmental parameters such as root zone temperature.

Temperature-based models have been developed to predict many aspects of growth and development, including flowering, fruit ripening, dormancy and seed germination (Thornley and Johnson, 1990). To our knowledge, there are no temperaturebased models that predict the stages of root formation in cuttings under different environments. Root formation in cuttings is affected by root zone temperature (Loach, 1988). Optimal root zone temperatures are between 18 and $30{ }^{\circ} \mathrm{C}$ depending on the species. In general, warmer temperatures tend to reduce the time to visible root formation and increase the number of roots per cutting up to a species-dependent temperature maximum. Temperatures above this maximum, typically about $30^{\circ} \mathrm{C}$, tend to have a deleterious impact on rooting. In poinsettia cuttings, Gislerød (1983) found that root formation was highest with a root zone temperature between 24 and $28{ }^{\circ} \mathrm{C}$ and that rooting was inhibited at $32{ }^{\circ} \mathrm{C}$ and below $20^{\circ} \mathrm{C}$.

There is evidence that the optimum temperature for the initial cell division stages of rooting is different from subsequent root elongation stages (Dykeman, 1976). Working with mum cuttings, Dykeman (1976) found that $30^{\circ} \mathrm{C}$ accelerated root formation, while $25^{\circ} \mathrm{C}$ was optimal for subsequent root growth. Carpenter et al. (1973) provide some evidence that temperature differentially impacts root formation and root elongation in poinsettia cuttings.

The objective of the current study was to develop root zone temperature-based mathematical models to predict time to visible rooting and postemergent root length in poinsettia cuttings under controlled environments and to validate these models by comparing observed vs. predicted rooting in greenhouse studies. 


\section{Materials and Methods}

Stock Plants AND Rooting Conditions. Poinsettia cuttings $(6$ to $8 \mathrm{~cm}$ ) were taken from greenhouse-grown stock plants maintained in 11-L containers. Cuttings were rooted either in controlled environment chambers (Wilkerson and Gates, 2003) or greenhouse mist beds (Wilkerson et al., 2005). Cuttings were stuck in $5 \times 5 \times 6 \mathrm{~cm}$ Anderson band containers (Anderson Manufacturing, Portland, Ore.) filled with a Metromix 350 (Scotts-Sierra Horticultural Products, Marysville, Ohio) and perlite [8:3 (v/v), $15.5 \mathrm{~g}$ dry weight] medium.

CONTROLLED ENVIRONMENT STUdies. The relationship between rooting stages and root zone temperature was established by rooting cuttings in three replicate environmental growth chambers that were designed to control root zone temperature, air temperature, air vapor pressure deficit (VPDair), and light. The construction of these chambers has been previously described in detail (Wilkerson and Gates, 2003; Zolnier et al., 2001). Briefly, cuttings in individual containers were placed in separate $68 \times 5$ $\times 5$-cm aluminum trays on an aluminum thermogradient plate within each chamber. Temperature gradients were established to provide root zone temperatures between 19 and $36^{\circ} \mathrm{C}$ depending on the experiment. The root zone temperature was monitored by thermocouples inserted into the rooting substrate at cutting base depth. Water was supplied to the rooting medium via a capillary mat system that maintained equal water tension amongst all trays (Geneve et al. 2003). Air temperature within the chambers was 24 ${ }^{\circ} \mathrm{C}$ and VPDair was $0.78 \mathrm{kPa}$. Light $(40-\mathrm{W}$ cool-white fluorescent tubes plus $100-\mathrm{W}$ incandescent bulbs) was provided for a $12-\mathrm{h}$ photoperiod with spatially averaged $P A R$ of $118 \mu \mathrm{mol} \cdot \mathrm{m}^{-2} \cdot \mathrm{s}^{-1}$. Just after cuttings were stuck the mist interval was set to $15 \mathrm{~min}$ and a duration of $5 \mathrm{~s}\left(\approx 1200 \mathrm{~mL} \cdot \mathrm{h}^{-1} \cdot \mathrm{m}^{-2}\right)$. The mist interval increased by $5 \mathrm{~min}$ at weekly intervals until cuttings were fully rooted.

TiME TO VISIBLE ROOTING MODEL. The relationship between root zone temperature and time to visible rooting was established in two separate controlled environment studies. In the first experiment, the thermogradient was between 19 and $28^{\circ} \mathrm{C}$, while in the second experiment it was between 27 and $36^{\circ} \mathrm{C}$. This provided a linear temperature gradient between the delimiting temperatures (Wilkerson and Gates, 2003) upon which five aluminum trays were placed. Each tray contained 14 cuttings with the two outer cuttings acting as border plants. Cuttings were evaluated daily to determine days to visible root emergence (any roots clearly protruding beyond the epidermis). There were 12 cuttings per temperature treatment in each environmental chamber. Rooting percentage and roots per cutting were evaluated $19 \mathrm{~d}$ after sticking.

The rate of development towards visible rooting was considered to be the inverse of the number of days to visible rooting for each cutting. The mathematical model that best represented this relationship was a nonlinear (Gaussian) equation (Eq. [1]).

$$
\hat{y}=a \exp \left[-0.5\left(\frac{x-b}{c}\right)^{2}\right]
$$

where

$\hat{y}=$ predicted variable: rate (per day).

$\mathrm{X}=$ mean daily root zone temperature $\left({ }^{\circ} \mathrm{C}\right)$.

$\mathrm{a}, \mathrm{b}, \mathrm{c}=$ coefficients determined from nonlinear regression.

Postemergent root elongation model. In order to avoid biasing root elongation measurements with the prior temperature used to initiate root primordia, separate controlled environmental chamber studies were conducted to measure postemergent root elongation. Cuttings were held in chambers with a root zone temperature of $24^{\circ} \mathrm{C}$ for $10 \mathrm{~d}$ poststicking to allow root primordia formation. At that time, cuttings were transferred to chambers with gradient root zone temperatures between 22 to $31^{\circ} \mathrm{C}$. There were five aluminum trays per chamber, each containing 14 cuttings. Three random cuttings from the inner 12 cuttings per tray in each chamber were removed for root length measurement every $3 \mathrm{~d}$. There were nine cuttings per temperature treatment per sampling day. In a second study, 10-d-old cuttings were moved to chambers with a constant root zone temperature of 24,26 , or $28^{\circ} \mathrm{C}$. Every $3 \mathrm{~d}, 12$ cuttings were removed from each chamber for root length measurements.

Total root length was measured in isolated roots from digital images captured on a flat bed scanner using MacRhizo software (Régent Instruments, Quebec, Canada) (Geneve and Kester, 2001). Accumulated thermal time was calculated as the summation of mean daily root zone temperatures from sticking or from visible root emergence. A thermal time model was derived from linear regression of accumulated thermal time vs. root length between 22 and $31{ }^{\circ} \mathrm{C}$. Postemergent root elongation rates were also calculated from linear regression equations for root elongation at each temperature. The relationship between temperature and root elongation rates was described using a nonlinear (Gaussian) mathematical equation as previously described.

Model VALIDATION STUDIEs. Mathematical models developed for time to visible rooting and postemergent root elongation were validated by comparing observed vs. predicted data obtained from six greenhouse experiments. Three-greenhouse mist chambers (1 $\times 1 \times 1.2 \mathrm{~m}$ ) were constructed using clear polycarbonate sheets supported on an aluminum frame (Geneve et al., 2003). Mist intervals were controlled by a personal computer running the evapotranspiration-based misting model developed by Zolnier et al. (2003). Each mist burst lasted $5 \mathrm{~s}$ and delivered water at 1200 $\mathrm{mL} \cdot \mathrm{h}^{-1} \cdot \mathrm{m}^{-2}$. The computer recorded root zone temperature from three thermal couples per chamber inserted in random containers at a depth equal to the cutting base. Data was recorded every 5 min and summed to provide a daily mean root zone temperature. Experiments were conducted approximately monthly from April to October. During June, July and August, greenhouse mist chambers received $60 \%$ shade; otherwise cuttings were in full sun. This provided a range of daily root zone temperatures from approximately 22 to $26^{\circ} \mathrm{C}$ (Fig. 1).

Each mist chamber contained 72 cuttings in a $9 \times 8$ arrangement. The inner 50 cuttings were evaluated for time to visible rooting and subsequent postemergent root elongation. Beginning $10 \mathrm{~d}$ poststicking, 10 random cuttings were nondestructively sampled for visible rooting. Nonrooted cuttings were placed back in their original position. Once rooting was observed, 10 random cuttings were measured for root elongation every $2 \mathrm{~d}$ as previously described. Time to visible rooting was determined as the time to $50 \%$ of the cuttings showing visible roots.

Visible root emergence was predicted from the growth chamber derived model using mean daily greenhouse root zone temperature when cumulative rooting progressed to day "n," $Y_{n}$, summed to a value of 1 , i.e., rooting on day " $n$ " if:

$$
Y_{n}=\sum_{i=1}^{n} \hat{y}_{i} \geq 1
$$

An adjusted model was also calculated that excluded daily mean temperatures below $21^{\circ} \mathrm{C}$ as a limiting base temperature.

Postemergent root elongation was predicted using daily 


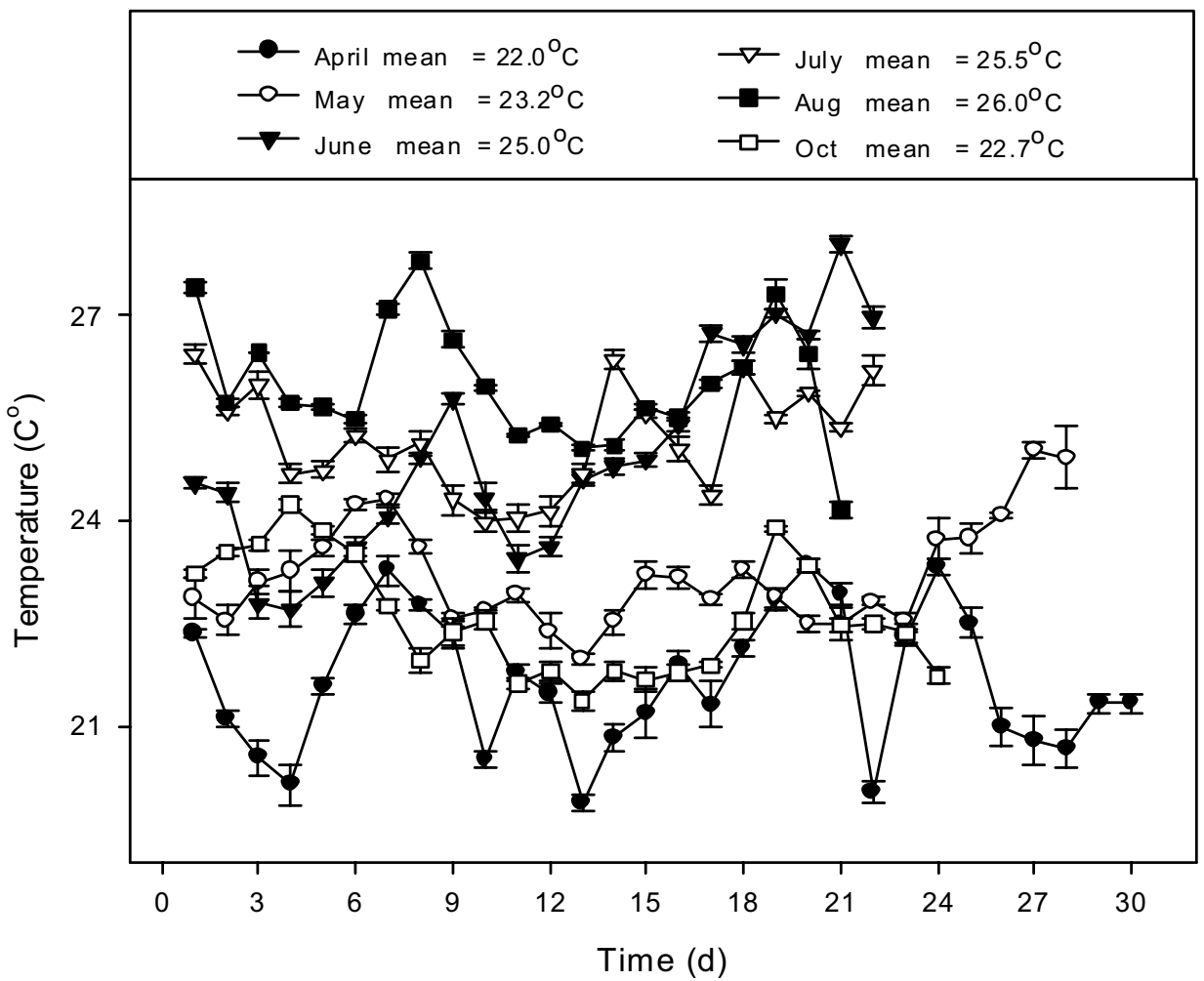

Fig. 1. Daily media temperature $( \pm \mathrm{SE})$ during poinsettia cutting propagation in the greenhouse at different times of the year.

mean greenhouse temperatures for both the thermal time and developmental progression models derived from the controlled environment studies.

Mean prediction error for observed vs. predicted values was calculated as the square root of the summation of squared residuals divided by sample size (Snipen et al., 1999). Coefficient of variation, standard error, and $P$ are also provided for each regression coefficient in nonlinear equations (SigmaPlot 8.0; SPPS, Chicago).

\section{Results}

TiMe TO VISIBLE ROOT EMERGENCE. In controlled environment rooting experiments, poinsettia cuttings rooted at their highest percentage, greatest root number per cutting, and fastest rate at constant root zone temperatures between 27 and $29^{\circ} \mathrm{C}$ (Table 1, Fig. 2). All three measures of rooting performance were reduced similarly as the temperature deviated from this optimal range.

It was not possible to accurately predict the time to visible root emergence using a linear root zone thermal time model (Thornley and Johnson, 1990). Thermal time calculated as the summation of daily mean root zone temperature (with or without subtraction of threshold base values below $24^{\circ} \mathrm{C}$ where rooting percentage was reduced) did not show any correlation with the observed time to visible root emergence (data not shown). However, thermal time was consistent for time to root emergence in controlled environment chambers with a constant root zone temperature between 24 and $29^{\circ} \mathrm{C}$. Accumulated thermal time degree days at these temperatures varied between 356 and $364($ mean $=360)$ and were not significantly different $(P=0.73)$. However, when 360 degree days was used to predict time to root emergence in six independent greenhouse rooting studies ranging with observed times to visible root emergence from 12 to $26 \mathrm{~d}$, the mean prediction error averaged across all trials was extremely high $(\mathrm{MPE}=16.8 \mathrm{~d})$ due mostly to the April experiment where root zone temperature was low (Table 2). Using a base value of $21^{\circ} \mathrm{C}$, the adjusted values for days to root emergence resulted in a better fit and mean prediction error was reduced to $6.5 \mathrm{~d}$.

The rate (inverse of the days to visible rooting) at which cuttings progress towards rooting at constant temperatures in environmental chamber was adequately described by nonlinear regression (Eq. [1]) calculated from data in Fig. 2A and coefficients presented in Table 3 . Based on this relationship, a model was developed to predict the days to visible root emergence. The model assumed that cuttings progressed toward rooting at a constant rate as a function of the daily mean root zone temperature.

The time to visible root emergence model was again tested for six greenhouse experiments (Table 2). Observed vs. predicted time to visible root emergence over the six experiments was highly correlated $\left(r^{2}=0.95\right)$ with a mean prediction error of $4.1 \mathrm{~d}$. The model was less effective for experiments conducted at low mean rooting temperatures. Threshold temperatures where rooting development was observed to be slow ( $>24 \mathrm{~d}$ ) or did not occur were approximately $\leq 20$ and $\geq 32{ }^{\circ} \mathrm{C}$ (Tables 1, 2, Fig. 2). An adjusted model was tested that assumed that no progress was made towards root emergence at root zone temperatures below 21 ${ }^{\circ} \mathrm{C}$. This adjusted model only affected the April experiment, but came closer to predicting the observed time to root emergence and improved the overall correlation between the observed and predicted days to root emergence $\left(r^{2}=0.98\right)$. The mean prediction error for the adjusted predicted values was $1.6 \mathrm{~d}$ (Table 2).

Postemergent root elongation. Postemergent root growth showed a linear increase over time at each temperature between 22 and $29^{\circ} \mathrm{C}$ up to $\approx 100 \mathrm{~cm}$ in total root length (Fig. 3). Subsequent root growth greater than $100 \mathrm{~cm}$ was accelerated due to root branching and was more typical of a logarithmic growth curve (data not shown). Growth rate $\left(\mathrm{cm}^{\cdot} \mathrm{d}^{-1}\right)$ was temperature dependent and permissive temperatures were similar to developmental rates for time to visible root emergence except the optimal temperature for the least time required for visible root emergence was approximately $2{ }^{\circ} \mathrm{C}$ higher than for optimal root elongation (28 vs. $26^{\circ} \mathrm{C}$; Fig. 2 ).

Accumulated thermal time was calculated from growth chamber studies as the summation of mean daily root zone temperatures from sticking or from visible root emergence. Correlation between root length and accumulated thermal time from initial sticking was poor $\left(r^{2}=0.27\right)$, but there was a good linear relationship $\left(r^{2}\right.$ $=0.68$ ) between root length and accumulated thermal time after visible root emergence (Fig. 4). Observed vs. predicted root length was compared for six greenhouse experiments using the linear thermal time model with an $r^{2}$ value of 0.69 and a mean prediction error of $14.6 \mathrm{~cm}$ (Fig. 5A).

Postemergent root growth was also described using a model calculated from temperature-derived growth rates shown in Fig. 
Table 1. Adventitious root formation in poinsettia cuttings in response to media temperature $19 \mathrm{~d}$ after sticking in growth chambers.

\begin{tabular}{ccc}
\hline Temp $\left({ }^{\circ} \mathrm{C}\right)$ & $\begin{array}{c}\text { Rooting percentage } \\
(\text { mean } \pm \mathrm{SD})\end{array}$ & $\begin{array}{c}\text { Roots per cutting } \\
(\text { mean } \pm \mathrm{SD})\end{array}$ \\
\hline 19 & 0 & 0 \\
22 & $77.8 \pm 22.2 \mathrm{~b}$ & $12.0 \pm 3.1 \mathrm{c}^{\mathrm{z}}$ \\
24 & $66.8 \pm 19.3 \mathrm{~b}$ & $18.8 \pm 5.2 \mathrm{~b}$ \\
27 & $100 \mathrm{a}$ & $26.8 \pm 3.9 \mathrm{a}$ \\
29 & $100 \mathrm{a}$ & $17.3 \pm 3.8 \mathrm{~b}$ \\
30 & $66.8 \pm 19.3 \mathrm{~b}$ & $6.7 \pm 3.4 \mathrm{~d}$ \\
31 & $33.8 \pm 0 \mathrm{c}$ & $2.2 \pm 1.1 \mathrm{de}$ \\
32 & $22.1 \pm 11.1 \mathrm{c}$ & $1.0 \pm 0.5 \mathrm{e}$ \\
33 & 0 & 0 \\
\hline
\end{tabular}

${ }^{2}$ Means \pm SD followed by the same letter within a column were not different by Tukey's test $(\alpha=0.05)$.

2B (calculated from Eq. [1] with coefficients in Table 3). There was a higher correlation $\left(r^{2}=0.82\right)$ between observed and predicted root length following root emergence using the nonlinear growth rate derived model compared to the linear thermal time model, but the mean prediction error of $14.8 \mathrm{~cm}$ was similar to the $14.6 \mathrm{~cm}$ found in the linear model (Fig. 5).

\section{Discussion}

The current study supports previous work establishing different temperature optima for root initiation and postemergent root elongation stages of adventitious root formation (Dykeman, 1976; Gislerød, 1983). The use of a thermogradient table in the current study permitted more root zone temperatures to be evaluated simultaneously compared to previous studies and allowed more precise temperature optima determination for these discreet rooting stages. Using poinsettia cuttings, Gislerød (1975) found that the time to visible root emergence was fastest with a root zone temperature between 25 and $27.5^{\circ} \mathrm{C}$. The current study found 27 to $28^{\circ} \mathrm{C}$ to be the temperature optima for the root initiation stage in poinsettia as indicated by reduced time to visible root emergence and the greatest number of roots per cutting (Table 1; Fig. 2).

Gislerød (1983) observed the greatest postemergent root growth at root zone temperatures between 24 and $29^{\circ} \mathrm{C}$, while the current study suggests that the more precise range appears to be 26 to 28 ${ }^{\circ} \mathrm{C}$ (Fig. 2, 3). Similar to previous work (Carpenter et al., 1973; Gislerød 1983), the high root zone temperature threshold for root emergence and elongation in poinsettia was approximately 31 and $33^{\circ} \mathrm{C}$ (Table 1, Fig. 2, 3). The low temperature threshold $\left(21^{\circ} \mathrm{C}\right)$ as determined by progression toward root emergence and postemergent root growth was slow (Fig. 2), which supports previous observations (Gislerød, 1983).

There are currently no published models estimating time to visible root emergence and postemergent root growth during cutting propagation. We hypothesized that rooting stages could be adequately predicted using root zone temperature as the sole environmental variable. This assumes adequate management of VPDair and rooting media moisture during cutting propagation.

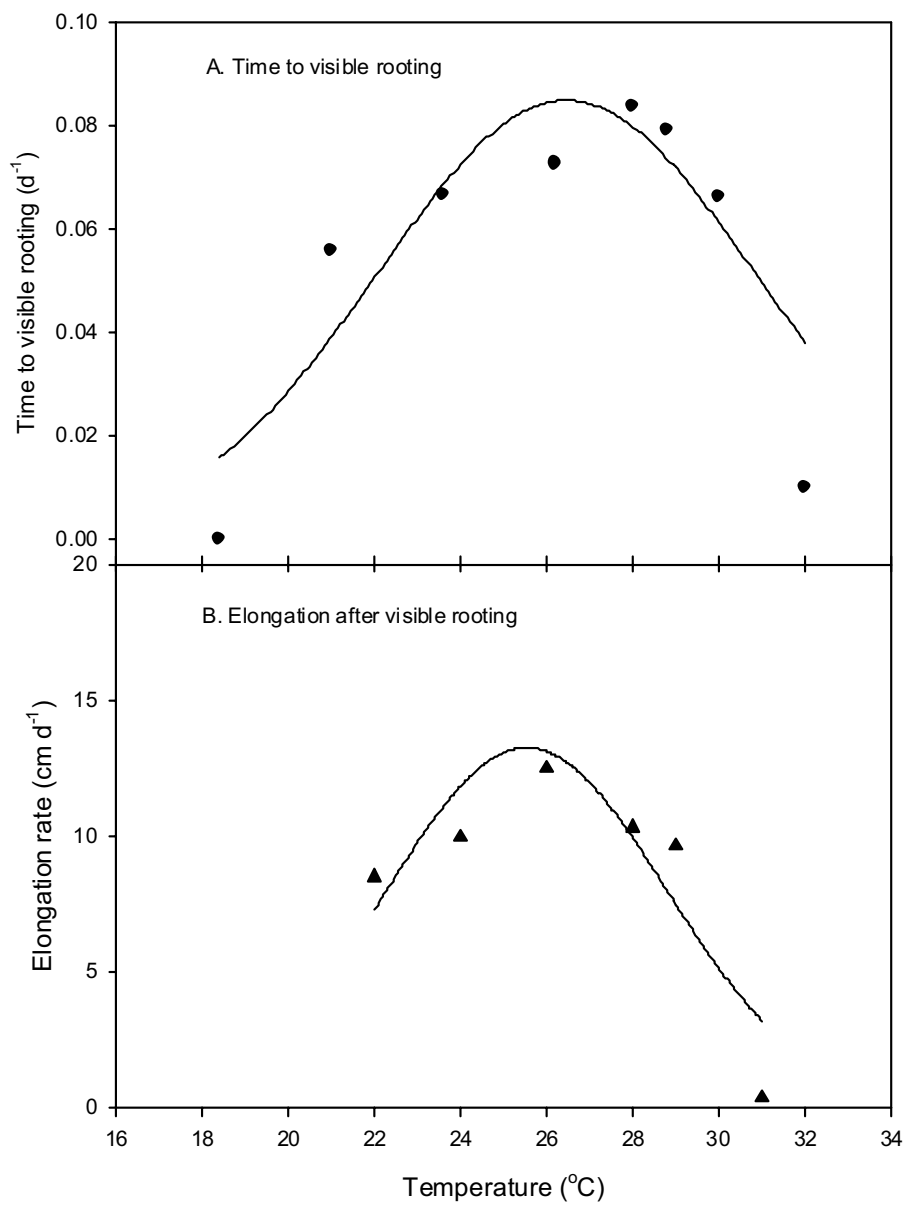

Fig. 2. Time to visible rooting and postemergent root length in poinsettia cuttings grown at different root zone temperatures in controlled environment chambers. (A) Rate of development towards rooting was computed as the inverse of the number of days to visible rooting. Regressing rooting rate vs. temperature was described by a nonlinear Gaussian relationship (Eq. [1]; $r^{2}=0.86$ ). (B) Root elongation rate for each root zone temperature described by nonlinear Gaussian regression $\left(r^{2}=0.80\right)$.

Previous studies have shown an interaction between root zone temperature and available water (oxygen) in the rooting medium on rooting in poinsettia cuttings (Gislerød, 1983). However, if saturation of the medium was avoided, temperature appeared to adequately describe the stages of root formation for poinsettia.

The approach adopted for this study was to develop mathematical models for time to visible root formation and postemergent root length under constant root zone temperatures in controlled environment chamber studies and use these models to predict rooting in greenhouse studies. Time to root emergence across temperatures showed a nonlinear distribution that could be described by a Gaussian equation (Fig. 2). Postemergent root growth was described equally well by a linear regression equation using accumulated thermal time or a Gaussian equation using temperature-based growth rates (Figs. 2, 4, 5). Wilkerson et al. (2005) showed that poinsettia cuttings were unable to remove water from the rooting medium prior to root emergence. They also showed that postemergent root elongation was linear with transpiration potential and that cuttings needed a minimum of 50 $\mathrm{cm}$ of total root length to maintain steady-state transpiration under a moderate VPDair stress. Zolnier et al. (2003) introduced the concept of a rooting coefficient into an evapotranspiration-based model to control misting during poinsettia cutting propagation. 
Table 2. The relationship between observed and predicted time to visible rooting in poinsettia cuttings using a thermal time or a temperature-based developmental progression model.

\begin{tabular}{|c|c|c|c|c|c|c|}
\hline \multirow{3}{*}{ Date } & \multirow{3}{*}{$\begin{array}{l}\text { Mean daily } \\
\text { temperature } \\
\left({ }^{\circ} \mathrm{C} \pm \mathrm{SE}\right)\end{array}$} & \multicolumn{5}{|c|}{ Time to visible root emergence $(\mathrm{d} \pm \mathrm{SE})$} \\
\hline & & \multirow[b]{2}{*}{ Observed } & \multicolumn{2}{|c|}{ Thermal time model ${ }^{\mathrm{z}}$} & \multicolumn{2}{|c|}{ Rate of development model } \\
\hline & & & Predicted & Adjusted $^{y}$ & Predicted & Adjusted $^{y}$ \\
\hline April & $22.0 \pm 0.2$ & $25.7 \pm 0.3$ & $17.0 \pm 0$ & $22.7 \pm 1.5$ & $21.7 \pm 0.7$ & $24.6 \pm 0.7$ \\
\hline May & $23.2 \pm 0.1$ & $18.0 \pm 0.3$ & $16.0 \pm 0$ & $16.0 \pm 0$ & $16.3 \pm 0.3$ & $16.3 \pm 0.3$ \\
\hline June & $25.0 \pm 0.3$ & $14.3 \pm 0.3$ & $15.3 \pm 0.3$ & $15.3 \pm 0.3$ & $14.3 \pm 0.6$ & $14.3 \pm 0.6$ \\
\hline July & $25.4 \pm 0.2$ & $12.3 \pm 0.3$ & $15.0 \pm 0$ & $15.0 \pm 0$ & $13.0 \pm 0$ & $13.0 \pm 0$ \\
\hline August & $26.0 \pm 0.2$ & $12.0 \pm 0.6$ & $14.0 \pm 0$ & $14.0 \pm 0$ & $12.7 \pm 0.3$ & $12.0 \pm 0$ \\
\hline \multirow[t]{2}{*}{ October } & $22.6 \pm 0.2$ & $18.7 \pm 0.7$ & $16.3 \pm 0.3$ & $16.3 \pm 0.3$ & $18.0 \pm 0.6$ & $18.0 \pm 0.6$ \\
\hline & & $\mathrm{MPE}^{\mathrm{w}}$ & 16.8 & 6.5 & 4.1 & 1.6 \\
\hline
\end{tabular}

${ }^{2}$ Thermal time was calculated as the number of days to 360 accumulated thermal days.

yAdjusted model excluded daily mean temperatures below $21^{\circ} \mathrm{C}$. Linear regression for observed vs. predicted; and observed vs. adjusted was $r^{2}=0.93$ and 0.98 , respectively.

wMean prediction error (d) is the square root of the summation of squared residuals divided by sample size.

Table 3. Nonlinear regression coefficients for equation 1 used to describe the relationship between temperature and either time to root emergence or postemergent root elongation in poinsettia cuttings.

\begin{tabular}{ccccc}
\hline \multirow{2}{*}{ Model } & Variables & $\begin{array}{c}\text { Coefficient of } \\
\text { variation (\%) }\end{array}$ & SE & $P$ \\
\hline \multirow{2}{*}{ Root emergence } & $\mathrm{a}$ & 0.0848 & 0.008 & 0.0001 \\
& $\mathrm{~b}$ & 26.455 & 0.52 & $<0.0001$ \\
Root length & $\mathrm{c}$ & 4.379 & 0.62 & 0.0009 \\
& $\mathrm{a}$ & 12.871 & & 0.006 \\
& $\mathrm{~b}$ & 25.597 & 0.55 & $<0.0001$ \\
& $\mathrm{c}$ & 3.29 & 0.70 & 0.018 \\
\hline$\hat{y}=a \exp \left[-0.5\left(\frac{x-b}{c}\right)^{2}\right]$ & & &
\end{tabular}

where:

$\hat{y}=$ predicted variable: daily rooting progression (per day), or root length $\left(\mathrm{cm} \cdot \mathrm{d}^{-1}\right)$.

$\mathrm{x}=$ mean daily root zone temperature $\left({ }^{\circ} \mathrm{C}\right)$.

$\mathrm{a}, \mathrm{b}, \mathrm{c}=$ coefficients determined from nonlinear regression.

The cutting coefficient was calculated from the transpiration potential of cuttings at different rooting stages (Wilkerson et al., 2005) and reflected the ability to remove water from the rooting medium. When the cutting was able to contribute to the overall water balance, misting intervals should be shortened to allow cuttings to begin to acclimate to nonmisted conditions. Using mean daily root zone temperature, the key rooting stages based on transpiration potential identified by Wilkerson et al. (2005) were readily identified using the temperature-based models developed in this study. These models were fairly robust and covered a wide range of root zone temperatures. However, because poinsettia is a seasonal crop, root zone temperatures during propagation (i.e., shaded greenhouse in June, July, August; Northern Hemisphere) are near optimal (Fig. 1) and within this temperature range the current models predict rooting stages with less than $1 \mathrm{~d}$ accuracy (Table 2). These models could be used independently to identify rooting stages to aid a propagator using static control systems or incorporated into dynamic misting systems such as the evapotranspiration-based misting model (Zolnier, 2003) to determine misting intervals with a greater degree of precision. 


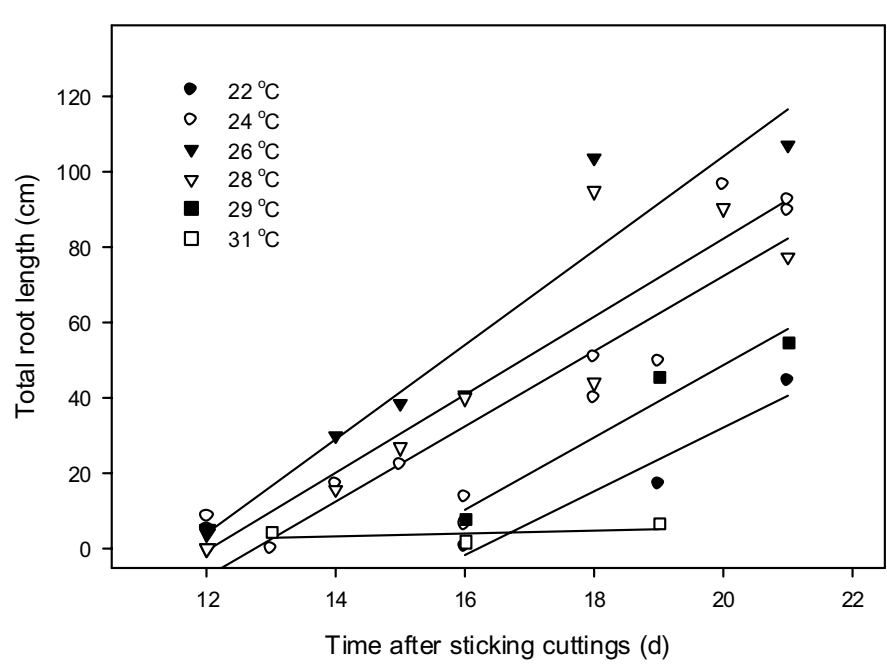

Fig. 3. Root elongation in rooted poinsettia cuttings grown at different root zone temperatures in controlled environment chambers. Linear regression for growth at $22,24,26,28,29,31^{\circ} \mathrm{C}$ showed $r^{2}$ values of $0.94,0.83,0.92,0.84,0.95$, and 0.19 , and slopes (growth rates in $\mathrm{cm}^{\cdot} \mathrm{d}^{-1}$ ) of $8.48,9.98,12.51,10.31,9.65$, and 0.35 , respectively.

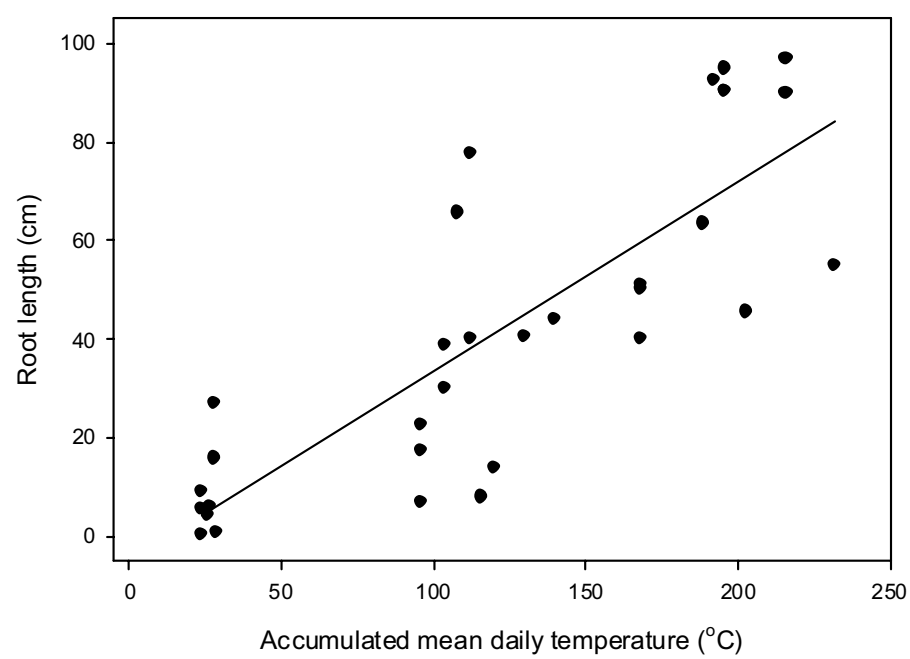

Fig. 4. Correlation between accumulated thermal time following visible rooting and total root elongation in poinsettia cuttings rooted in different root zone temperatures in the controlled environment chambers. Linear regression was [y $($ root length $)=0.384 \times($ temperature $)-4.92$ ] $; r^{2}=0.68$.

\section{Literature Cited}

Carpenter, W.J., E.N. Hansen, and W.H. Carlson. 1973. Medium temperatures effect on geranium and poinsettia root initiation and elongation. J. Amer. Soc. Hort. Sci. 98:64-66.

Dykeman, B. 1976. Temperature relationship in root initiation and development of cuttings. Proc. Intl. Plant Prop. Soc. 26:201-207.

Geneve, R.L. and S.T. Kester. 2001. Evaluation of seedling size following germination using computer-aided analysis of digital images from a flat bed scanner. HortScience 36:117-20.

Geneve, R.L., S.T. Kester, and J.W. Buxton. 2003. Capillary mats alter the water content in medium during mist propagation of Dendranthema. HortScience 39:584-587.

Gislerød, H.R. 1975. The influence of temperature and water potential on rooting of poinsettia cuttings (Euphorbia pulcherrima L. 'Lady'). Acta Hort. 54:127-136.

Gislerød, H.R. 1983. Physical conditions of propagation media and their influence on the rooting of cuttings: III. The effect of air content and temperature in different propagation media on the rooting of cuttings. Plant Soil 75:1-14.

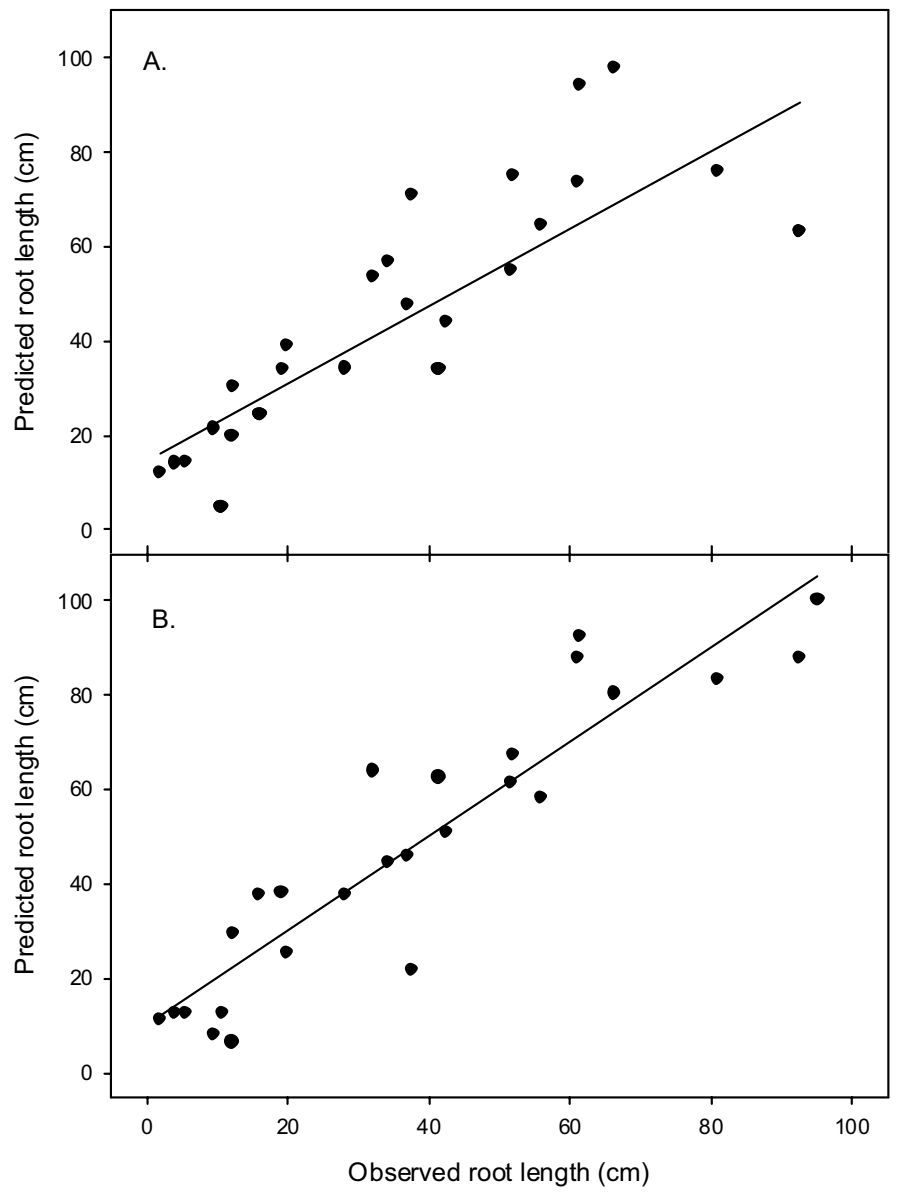

Fig. 5. Observed vs. predicted root length in poinsettia cuttings following root emergence in six greenhouse experiments using (A) a thermal time model derived from linear regression of accumulated thermal time vs. root length from growth chamber studies; $r^{2}=0.68$ or $(\mathbf{B})$ a nonlinear model calculated from temperature-derived growth chamber growth rates; $r^{2}=0.82$. Mean prediction error $(\mathrm{cm})$ calculated from the square root of the summation of squared residuals divided by sample size was 14.6 and $14.8 \mathrm{~cm}$ for the linear and nonlinear regression models, respectively.

Hartmann, H.T., D.E. Kester, F.T. Davies, Jr., and R.L. Geneve. 2002. Hartmann and Kester's plant propagation: Principles and practices, Seventh ed. Prentice Hall, Upper Saddle River, N.J.

Loach, K. 1988. Controlling environmental conditions to improve adventitious rooting, p. 248-273. In: T.D. Davis, B.E. Haissig, and N. Sankhla (eds.). Adventitious root formation in cuttings. Dioscorides Press, Portland, Ore.

Snipen, L.G., R. Moe, and J. Søreng. 1999. Influence of potential growth factors in predicting time to flowering in poinsettia (Euphorbia pulcherrima). Scientia Hort. 81:345-359.

Thornley, J.H.M. and I.R. Johnson. 1990. Plant and crop modeling - A mathematical approach to plant and crop physiology. Clarendon Press, Oxford.

Wilkerson, E.G. and R.S. Gates. 2003. Controlled environment system for studying root zone temperature effects on cutting propagation. Appl. Eng. Agr. 19:483-489.

Wilkerson, E.G., R.S. Gates, S. Zolnier, S.T. Kester, and R.L. Geneve. 2005. Transpiration capacity in poinsettia cuttings at different rooting stages and the development of a cutting coefficient for scheduling mist. J. Amer. Soc. Hort. Sci. 130:in press.

Zolnier, S., R.S. Gates, R.L. Geneve, and J.W. Buxton. 2002. Surface diffusive resistances of rooted poinsettia cuttings under controlledenvironment conditions. Trans. Amer. Soc. Agr. Eng. 44:1779-1787.

Zolnier, S., R.S. Gates, R.L. Geneve, and J.W. Buxton. 2003. Evapotranspiration model-based mist control for poinsettia propagation. Trans. Amer. Soc. Agr. Eng. 46:135-145. 